DOI: $10.17805 /$ zpu.2016.2.17

\title{
Концептуальные основы системы управления в Японии
}

\author{
Г. А. ГВОЗДЕВСКАЯ \\ (МОСКОВСКИЙ ГУМАНИТАРНЫЙ УНИВЕРСИТЕТ)
}

В статье представлено исследование системы управления в Японии как феномена синтеза этики, эстетики, религии. Автор использовал методологический подход, основанный на комплексном анализе философского фундамента японской структуры управления, и показал неразрывную связь религиозно-философской трактовки власти, принципов толерантности, традиционных социальных концепций, речевого этикета в японской модели управления.

В исследовании акцентируется внимание на уникальности японской самобытной трактовки власти, имеющей корни синтоистского и конфуцианского происхождения, принципиальной важности в управлении не только порядка соподчинения, но и абсолютной гармонии со-бытия всех ступеней. Реализация принципа ша («гармонии») рассматривается в русле концепций: ittaikan («чувство единства»), оyakokankei («отношения родитель ребенок»), атае (чувство зависимости).

Управление в Японии рассматривается как искусство, обладающее богатым набором средств выражения основных принципов. Среди них особо отмечается техника принятия решений nemawashi («вращение вокруг корня»), стиль общения - убеждения settoku, принципы коммуникации ishindenshin («от сердца к сердцу»).

В статье прослеживается также глубокая взаимосвязь философии толерантности и искусства управления в японской традиции. Основное внимание уделяется характеристике социально-философских концепций, которые явились фундаментом иерархической структуры японского социума.

Данные традиционные концепции присутствуют в современной Японии не только на уровне теоретического постулата, но и в реалиях механизма управления всех уровней - от небольших коллективов до крупных предприятий, компаний и государства в целом. Результаты исследования позволяют представить иерархическую структуру управления Японии как целостный комплекс, отражающий характерную онтологию миропонимания, раскрывают механизм руководства, обеспечивающий высокий темп экономического развития страны.

Ключевые слова: Япония; управление; концепция управления; японский этикет; японская традиция; японский стиль коммуникации 


\section{ВВЕАЕНИЕ}

$\mathrm{O}$ бращение к исследованию японской концепции управления сегодня актуально Аля России, переживающей экономический кризис, с точки зрения возможности использования идей японского стиля руководства, обеспечивающих высочайший уровень корпоративной ответственности и качества, которым трудно найти аналог в мире. Япония демонстрирует на протяжении многих десятилетий уникальные показатели технического прогресса, экономической стабильности в условиях ограниченности природных ресурсов, стихийных бедствий.

Мы считаем, что одной из главных причин таких высоких экономических показателей является то, что Япония с древнего периода до настоящего времени остается верной принципу трактовки власти, адекватной форме религиозной аскетики, идее «управления - служения». Пример Японии ярко показывает действенность и жизнеспособность конфунцианской концепции «мудрого правителя», феномена надындивидуального сознания в иерархической структуре управления.

Анализ японской системы управления представлен в ряде отечественных и зарубежных исследований. Они большей частью посвящены характеристике уникальной модели японского менеджмента, раскрытию ее исторических истоков, сравнению с американскими и европейскими аналогами (Арская, 1991; Веретнов, 2009: Электронный ресурс; Кнорринг, 2001; Курицын, 1994; Симхович, 2002; Шарко, 2007; Гвоздевская, 2013ab; Nakane Chie, 1967 и др.).

В настоящей статье акцентируется внимание на раскрытии механизмов взаимодействия социальных концепций с философско-мировоззренческим комплексом традиционной Японии, которые явились основой отношения к управлению, с одной стороны, как к средству реализации основной функции власти, с другой - как к искусству поддержания состояния гармонии во всех иерархических структурах государства и социума. Методологический подход, основанный на исследовании философских основ отдельных сторон японского менеджмента, представлен в отечественной науке (к примеру, в статье $\Lambda$. Б. Кареловой (Карелова, 2013) прослеживается связь буддийского миропонимания и корпоративной социальной ответственности в Японии). Настоящая работа продолжает данное направление, но ставит более широкую задачу анализа различных сторон японской системы управления в целом: философской трактовки власти, принципов толерантности, роли традиционных социальных концепций, речевого этикета.

\section{ТРАКТОВКА ВААСТИ В ЯПОНСКОЙ ТРААИЦИИ}

Основные принципы государственной системы управления Япония заимствовала у Китая вместе с буддизмом и конфуцианством. Конфуцианская модель оказалась действенной до настоящего времени. Ее базовые принципы: иерархическое подчинение, строгая упорядоченность, добровольное служение низших высшим. Как пишет И. А. Василенко, здесь «отношения между высшими и низшими подобны отношениям между ветром и травой. Трава должна склониться, если подует ветер» (Василенко, 2000: 860). Аристократизм духа правителя - «ученого мужа» по конфуцианской доктрине, сакральное происхождение власти императорского рода согласно синтоистским представлениям породили модель управления, в основе своей отличную от западной. Японский исследователь Наканэ Чиэ (Nakane Chie) впервые в 1967 г. представил теоретический анализ данной модели, охарактеризовав ее как tateshakai «вертикальное общество», имея в виду иерархический принцип организации в проти- 
воположность западной, названной им уоkoshakai - «горизонтальное общество» (Nakane Chie, 1967).

Уникальность японского самобытного, детально продуманного подхода к трактовке власти имеет корни синтоистского происхождения с характерной идеей одухотворенности всего сущего. В иерархии японского социума важен не только порядок соподчинения, в ней должна царить абсолютная гармония со-бытия всех ступеней. Она многогранно проявляется через ittaikan - «чувство единства», oyakokankei (отношения "родитель - ребенок») - межличностные отношения, построенные по образцу родственных семейных, ninjyou - чувство любви, заботы старших (по возрасту, положению и т. д.) о младших.

Приведенные выше термины представляют собой социальные концепции, действующие в современной Японии не только как теоретические постулаты, идеальные точки отсчета, но и как реалии, представленные в механизме управления всех уровней от небольших коллективов до крупных предприятий, компаний и государства в целом. Японец стремиться быть членом различных сообществ, ибо они способны дать человеку ощущение защищенности, безопасности. В русле японской традиции функция власти реализуется через основной приниип концепиии атае - обеспечение заботы о подчиненных, которые воспринимают подчинение как естественное стремление к зависимости. Аанный феномен исследовал в своем фундаментальном труде «Анатомия Зависимости» известный японский психоаналитик Аои Такэо (Doi Takeo, 2002).

\section{ОСНОВНЫЕ ПРИНЦИПЫ СИСТЕМЫ УПРАВАЕНИЯ В ЯПОНИИ}

Управление в Японии можно рассматривать как искусство, которое обладает богатым набором средств выражения основных принципов. Среди них особенно следует отметить технику принятия решений nemawashi («вращение вокруг корня»), стиль общения - убеждения settoku, принцип компромиса dakyou. Остановимся на них поАробнее.

Слово nemawashi в точном переводе звучит как «окучивание корня» как необходимое условие для пересадки растения, в переносном смысле трактуется как закладывание основы. В японской политике, сфере деловых отношений, производстве и т. А. nemawashi стало базовым принципом, который обусловливает длительный подготовительный период, предшествующий введению каких-либо изменений в существующий порядок: принятию решений, законопроектов и т. А. Эта стадия «черновой» работы включает в себя переговоры с заинтересованными сторонами, глубокий анализ потенциально возможных противоречий, многоступенчатые совещания, проводимые часто в неформальной обстановке с целью достижения согласия сторон. Nemawashi позволяет максимально избегать конфликтов и степени рисков, потенциально возможных вследствие каких-либо трансформаций.

В одной из статей американского исследователя и практика в области медицины A. Арбор (A. Arbor) приводится следующий пример, конкретизирующий реализацию принципа nemawashi: «Когда я инициировал проект, мой японский советник приложил большие усилия для объяснения необходимости петаwashi, чтобы получить одобрение в моей принимающей организации. Он подчеркнул важность тщательного информирования каждого сотрудника клиники и администрации, которые могли бы быть затронуты при реализации предлагаемого проекта. Было необходимо предусмотреть также шаги, необходимые для получения их одобрения. Этот процесс занял три недели, и личные переговоры проходили на шести уровнях, прежде чем окончатель- 
ное утверждение проекта было предоставлено» (Arbor, 1995: Электронный ресурс; перевод наш. $-\Gamma$. Г.).

Процесс nemawashi делится на определенные составляющие:

1) ступень до публичного проявления конфликта, работа по его предупреждению на основе прогнозирования и анализа противоречивых точек зрения, максимальная степень взвешивания полярных позиций;

2) работа, проводимая после того, как противоречия ясно, отчетливо прослеживаются, с применением техники убеждения settoku;

3) работа по преодолению разногласий, возникших в процессе проведения переговоров, совещаний.

Современной тенденцией реализации принципа петаwashi является создание в структуре системы управления японских компаний звена, отвечающего за коллегиальные решения. Так, к примеру, на официальном сайте компании Рanasonic представлена информация о 37 подразделениях фирмы, создании Штаба корпоративной стратегии для осуществления функции стратегии управления всей группы, совещаниях данного «штаба» с Советом по важным делам группы (Keieirinen: Электронный ресурс).

Принцип компромисса dakyou предполагает снижение уровня собственных требований в случае кардинальных разногласий, попытку найти выгоду не в категоричном отстаивании своей позиции, а в желании (даже при внутренней убежденности в абсолютной правильности своего мнения) сделать шаг навстречу партнеру во имя согласия и сохранения дальнейшей перспективы сотрудничества. Интересно отметить, что в японское понятие go: $i$ «согласие» входят два иероглифических знака, первый из которых go: - понимается как собственно «согласие», второй $i$ - подразумевает разум, состоящий, в свою очередь, из двух смысловых единиц oto и kokoro, которые могут трактоваться как «звук души». Таким образом, этимологически подтверждается древнеяпонская определяющая идея всемогущества kokoro (духа, души), стремление к изначальной гармонии во всем, включая деловые отношения. В русле характерного миропонимания, сложившегося в Японии с момента основания государства, основная функция управления рассматривается как процесс урегулирования противоположных позиций, решение конфликтов во имя достижения всеобщих выгод.

В контексте японской социальной концепции oyakokankei (отношения «родитель - ребенок») в системе управления имеет место принципиально отличная от западной трактовка лидера, главная задача которого не авторитарное руководство и не только контроль за исполнением указов, а достижение $w a-$ гармонии отношений внутри коллектива, группы, обеспечение комфортной межличностной коммуникации. В японском глаголе michibiku ( «руководить») присутствует иероглифический знак Пути. Этот символ наполняет понятие руководства философским смыслом конфуцианства и даосизма с характерной идеей трактовки управления как исповедимого Пути следования древним канонам, подчинения воле Неба.

Принцип oyakokankei заложен во всей иерархической структуре японских компаний с характерной системой «пожизненного найма», льгот за выслугу лет, детально продуманной системой социальных компенсаций и ряда других мер, гарантирующих заботу и ответственность со стороны руководства, подобную семейной ${ }^{1}$. Японские компании предоставляют своим работникам на льготной основе займы для покупки жилья, стремятся приобрести жилье для работников в одном районе с целью установления дружеских контактов вне работы, оплачивают большую часть медицинских 
расходов, зарубежные стажировки и т. А. (Симхович, 2002: 115). Аанный тип руководства кадрами определяется как «промышленная семейственность». А. Козлов считает, что такая философия предпринимательства находит свое выражение в долгосрочной занятости и том большом значении, которое придается стажу: «...ни один член "семьи" при увольнении из компании не должен быть оставлен без заботы о его будущем, даже в тяжелые времена. Со старшими членами "семьи" обращаются более почтительно, чем с младшими, потому что длительный стаж указывает на верность компании и большой опыт - рабочий и жизненный» (Козлов, 2002: 123).

Принцип oyakokankei имеет многогранное проявление в японской корпоративной культуре. Многие японские компании изначально создавались на основе семейного бизнеса и на протяжении всей истории своего существования демонстрировали верность единым концептуальным установкам. Ярким примером в этом отношении является известная компания «Тоёта». Управляющий директор Гэри Конвис, называя кредо менеджмента данной компании «Аао Тoyota», говорит о его «генетическом коде», сформированном с момента основания и передаваемом из поколения в поколение. «Аао Toyota состоит из двух компонентов: непрерывного совершенствования и уважения к людям... Уважение к людям выражается в том, что компания обеспечивает им гарантированную занятость и побуждает каждого члена команды стремиться к достижению более высоких результатов» (цит. по: Аайкер, 2012: 20). Все сотрудники японских компаний, подобно членам семьи, должны разделять единые мировоззренческие принципы и методы ведения бизнеса своей фирмы. Отношения обоюдной ответственности управленцев и служащих также можно рассматривать как аналог родственных уз. В данном контексте часто имеющие место факты отказа японских работников от оплачиваемого отпуска, добровольное выполнение сверхурочной работы даже без предупреждения со стороны руководства и др. выступают как вполне естественная форма корпоративного поведения, основанная на абсолютном доверии и уверенности в своей социальной защищенности, равносильной модели семейных отношений.

В исследовании $\Lambda$. Б. Кареловой рассмотрена буддийская концепция jiri rita («получай пользу для себя, принося пользу другим») как религиозно-философское основание японского феномена социальной ответственности. В качестве практического примера современной реализации данной концепции автор приводит программные лозунги компании Sumitomo, в которых в качестве одной из целей бизнеса дана установка на принесение пользы государству и обществу (Карелова, 2013). Ориентация предпринимательской деятельности на общественное благо представлена на официальных сайтах ведущих японских компаний. К примеру, в корпоративных ценностях компании Ajimoto Group обозначена следующая цель - «создавать корпоративную культуру, в которой каждый из нас может служить обществу как настоящий гражданин», компании Yamanouchi Group - «гармоничные отношения, основанные на честном бизнесе и защите окружающей среды», компании Shoei Sangyo Co - «быть частью общества, как живой человек, а не простой потребляющий организм, понимать, что без потребителя в нашем существовании не было бы смысла» (Тарасова, 2003: 125).

Следует отметить, что специфика стратегии руководства в Японии прежде всего исходит из трактовки цели бизнеса, кардинально отличной от западной. В исследовании профессора Государственного университета Ёкохама Ёсимори Масару приведены результаты опроса, проведенного в Японии, США, Греции, Германии, Франции по 
определению основной миссии фирмы. С положением «Вследствие того что акционеры являются собственниками компаний, основная задача последних - увеличение их прибыли» согласились 76\% американцев, 71\% греков и только 2,9\% японцев (Yoshimori Masaru, 1998: Электронный ресурс; перевод наш. - Г. Г.). Однако с определением фирмы как организации, направленной на увеличение прибыли всех заинтересованных сторон (работников, клиентов, акционеров, поставщиков и др.), ситуация оказалась противоположной. Согласие с данным определением выразили $97 \%$ японцев, $30 \%$ греков, 24\% американцев (там же). Внутри японской корпоративной модели интересы работника компании рассматриваются как первичные, и руководители несут моральную ответственность за их удовлетворение. Можно сказать, что здесь имеет место своеобразный «кодекс чести» руководителя по отношению к подчиненному. Японская модель показывает действенность принципа прямой пропорциональной зависимости социальной защищенности сотрудника компании и степени его ответственности, трудоспособности, конкретного вклада в общее дело.

\section{ФИАОСОФИЯ ТОАЕРАНТНОСТИ И ИСКУССТВО УПРАВАЕНИЯ}

\section{В ЯПОНСКОМ СОЦИУМЕ}

Характерной особенностью японской традиции является то, что толерантность здесь не провозглашается как теоретический постулат, но действует как принцип жизни, бытия в социуме, где индивидуальное «я» не самодостаточно, а со-настроено с окружающим. М. В. Шарко пишет: «...сформировавшаяся этическая система возвела приличия до уровня необходимости в социальных отношениях, в которых соблюдается не просто вежливость, имеющая черты внешних аксессуаров приличия, а должная вежливость как точное исполнение правил поведения в обществе, скрупулезного исполнения того, что требуется, а не того, что вздумается. Точное исполнение приличий и есть сам этикет. Назначение этикета состоит в нравственном воспитании - это есть дисциплина» (Шарко, 2007: 104).

На всех уровнях иерархии управления в Японии с периода древности до настоящего времени действует единый закон, о чем пишет В. И. Мильдон: «Не противопоставлять себя всему, что есть не он. Аюдской суд, в отличие от Божьего, требует сосуществования, а не противостояния» (Мильдон, 1992: 202).

В Японии всегда стремились удерживать авторитет власти не насильственным путем, а воспитанием социума в русле религиозных философских концепций, где смысл бытия индивидуального «я»- в подчинении и служении интересам «не я», растворении в «другом», в принципе - быть «тенью» другого (например, принципе служения самурая своему господину).

Можно сказать, что подчинение вышестоящим в японской традиции носит характер служения, подобно служению в религиозном смысле, подразумевающему отречение от собственного эго. Механизм воспитания надличностного сознания складывался в Японии веками, синтоистское миросозерцание основывалось на слиянии индивидуального «я» с природной стихией, буддийское - с высшим «я» внутри себя и через него с абсолютом.

\section{ВЗАИМОСВЯЗЬ ИСКУССТВА УПРАВАЕНИЯ И ПРИНЦИПОВ КОММУНИКАЦИИ В СОВРЕМЕННОЙ ЯПОНИИ}

Смирение, скромность, покорность как норма религиозного культа стала идеалом бытия в японском социуме. Выработанные в нем каноны учтивой вежливости, покло- 
нов, строго закрепленных за определенными ситуациями языковых клише и моделей поведения способствуют поддержанию тонуса особой человеческой теплоты в деловых отношениях. Искусство управления в Японии проявляется внутри самобытной системы коммуникации, настроенной на камертон состояния партнера, тонкого улавливания нюансов вибрации его kokoro.

Тип коммуникации в стиле ishindenshin («от сердца к сердцу»), сохранившийся в Японии на протяжении тысячелетий, принципиально отличен от европейского стиля общения. Здесь нет цели убеждения, аргументированного отстаивания своей правды, логики сократической беседы в цепи «тезис - антитезис». Аиалог в японском стиле коммуникации подобен ансамблю традиционных инструментов, где участники без дирижера интуитивно чувствуют состояние партнера, согласуют с ним ритм, темп, интонацию за счет улавливания тонких вибраций, предчувствования, предощущения.

В принципах японской коммуникации не случайно можно обнаружить закономерности, действующие в различных видах традиционного искусства Японии. Их объединяют общие философские, метафизические истоки. К примеру, беседа в японской традиции строится по закону поэтического жанра рәнга - «нанизывания строк», где верхнюю и нижнюю строку стиха сочиняли поочередно разные люди, но все они оказывались созвучны по внутреннему эмоциональному состоянию, взаимодополняли друг друга. В японском общении (и в повседневном, и в официально-деловом), так же как и в традиционной поэзии и прозе, высказанное является намеком на несказанное, подобно как «в Исэ моногатари автор провоцирует сознание читателя на доделку сочинения, восприятие читателя дополняет незаполненное» (Мильдон, 1992: 160), так и в диалоге особую значимость приобретает душевный отклик уојуо:, позволяющий слышать в интонациях собеседника, в «живущих паузах» ikita ma - скрытую сущность, более важную, чем вербально выраженное.

В японском языке веками вырабатывались механизмы такого стиля коммуникации, в котором первична этика смирения «я», возвышения собеседника, поддержания тонуса благодарности, учтивости, сохранения атмосферы бесконфликтности, доброжелательности, гармонии независимо от реалий содержания беседы, дискуссии и т. А.

Речевой этикет в японском бизнесе строится на принципах, свойственных в целом Аля всех типов коммуникации. Главный из них - kokoro de hanasu («говорить сердцем»), предполагающий тонкую сонастроенность на состояние партнера в момент диалога, избегание формальной холодной интонации, произнесение благодарностей и извинений одновременно с установленным в традиции низким поклоном (даже при телефонных переговорах), чтобы увеличилась степень интонационной теплоты и проникновенности, избегание конфликтности, категоричности при решении проблем. Еще один принцип - koe de aite no kokoro wo ugokasu ( «голосом приводить в движение сердце партнера»). Аля развития такой способности в бизнесе разработана система специальных тренингов, включающих методы релаксации, формирования внутреннего положительного настроя через образ, умения разговаривать с улыбающимся лицом, независимо от реального психологического состояния, беспокойства, физической усталости и т. А. Особое внимание уделяется владению искусством распределения та ( «пауз») в публичных выступлениях для усиления смысловых акцентов в предлагаемой информации.

В целом концепцию та как остановки, необходимой всем людям и управленцам, в первую очередь для сохранения состояния равновесия в бурной динамике XXI в., можно считать одной из определяющих в японской социальной философии. Сочета- 
ние напряженности рабочего повседневного ритма и созерцательности - уникальное достижение японской традиции, возведенное в ранг государственной политики настоящего времени, направленной на поддержание тонуса $w a$ (изначальной гармонии) в иерархии системы управления.

\section{ЗАКАЮЧЕНИЕ}

В Японии с периода древности до настоящего времени имеет место система управления, основанная на синтезе этики, эстетики, религии, построенная на фундаменте социально-философских концепций. Аанная система доказала свою жизнеспособность, обеспечила экономическую стабильность и высокий темп прогресса страны в различных областях. Результаты исследования, представленные в настоящей статье, позволяют раскрыть причины «японского чуда», исходящие из онтологии миропонимания, отражающие константы мировоззренческих комплексов, пронесенные через века. Как было показано, этика смирения индивидуального эго, толерантная коммуникация, уникальное со-бытие динамики современного ритма и созерцательности, вездесущее стремление к изначальной гармонии - звенья единой цепи проявления духовной составляющей философии власти в Японии. Комплексный анализ данного феномена сегодня имеет большое значение для России с точки зрения открытия перспектив построения отечественной концепции управления, основанной прежде всего на нравственном воспитании личности руководителя, коллегиальности принимаемых решений, выработке механизмов социальной защищенности служащих.

\section{ПРИМЕЧАНИЕ}

1 Примеры, характеризующие данное положение, представлены в ряде исследований (Арская, 1991; Веретнов, 2009: Электронный ресурс; Курицын, 1994, Симхович, 2002 и др.).

\section{СПИСОК АИТЕРАТУРЫ}

Арская, А. П. (1991) Японские секреты управления. М. : Универсум. 118 с.

Василенко, И. А. (2000) Политическая глобалистика : учеб. пособие для вузов. М. : Аогос. $360 \mathrm{c.}$

Веретнов, В. И. (2009) Японский опыт управления бизнесом [Электронный ресурс]// Проза.py. URL: http://www.proza.ru/2009/10/11/919 (дата обращения: 12.12.2015).

Гвоздевская, Г. А. (2013а) Иерархическая структура японской философии, социума, языка: образцы и исполнение // Культура - равновесие и гармония будущего мира : сб. науч. тр. М. : Академия ГПЧ МЧС России. 192 с. С. 44-49.

Гвоздевская, Г. А. (2013b) Этикет как главная составляющая иерархического порядка японского социума // Материалы междисциплинарной научно-практической конференции с международным участием «Культура и безопасность в современном мире». М. : Академия ГПЧ МЧС России. 229 с. С. 84-86.

Карелова, А. Б. (2013) Принципы буддийской и конфуцианской этики в формировании концепции корпоративной социальной ответственности в современной Японии // Япония. Ежегодник. № 42. С. 89-100.

Курицын, А. Н. (1994) Секреты эффективной работы: опыт США и Японии для предпринимателей и менеджеров. М. : Изд-во стандартов. 197 [1] с.

Кнорринг, В. И. (2001) Теория, практика и искусство управления : учебник для вузов по специальности «Менеджмент». 2-е изд., изм. и доп. М. : НОРМА (ИзА. группа НОРМА ИНФРА-М). 528 с.

Козлов, А. А. (2002) Управление персоналом в японских корпорациях в условиях глобализации экономики // Менеджмент в России и за рубежом. № 2. С. 122-128. 
Аайкер, Аж. (2012) Аао Тoyota: 14 принципов менеджмента ведущей компании мира Ажеффри Аайкер : пер. с англ. М. : Альпина Паблишер. 412 с.

Мильдон, В. И. (1992) Бесконечность мгновения (национальное в художественном сознании). М. : Советский писатель. 432 с.

Симхович В. А. (2002) Истоки современной японской системы управления // Проблемы теории и практики управления. № 6. С. 114-120.

Тарасова, Т. В. (2003) «Три кита» японского маркетинга // Маркетинг в России и за рубежом. № 6. С. 119-135.

Шарко, М. В. (2007) Японская вежливость и национально стилизованные константы дипломатии // Полигнозис. № 1 (29). С. 96-105.

Arbor, A. (1995) Nemawashi essential for conducting research in Japan [Электронный ресурс]// Social science \& medicine. № 41(3). URL: http://www.ncbi.nlm.nih.gov/pubmed/7481931\# (дата обращения: 12.12.2015).

Doi Takeo (2002). The Anatomy of Dependence. Toukyou : Kodansha. 192 p.

Keieirinen [Философия управления] [Электронный ресурс] // Panasonic (официальный сайт). URL: http://www.panasonic.com/jp/corporate/management/governance.html (дата обращения: 01.01.2016).

Nakane Chie (1967) Tateshakai no ningen kankei: tan'itsu shakai no riron [Взаимоотношение людей в иерархическом обществе]. Tōkyō : Kōdansha, Shōwa 42. 189 p. (На яп. яз.).

Yoshimori Masaru (1998) Kigyou wa dare no mono ka. Kigyougainen no nichibeiouhikaku [Комy принадлежит компания? - Сравнение японских, американских, европейских концепций] [Электронный ресурс] // Niftyhomupejisabisu. URL: http://myoshimori.world.coocan.jp/papers/6.pdf (дата обращения: 15.01.2016). (На яп. яз.).

Аата поступления: 15.01.2016 г.

\section{CONCEPTUAL FOUNDATIONS OF THE SYSTEM OF CORPORATE GOVERNANCE IN JAPAN \\ G. A. GVOZDEVSKAIA \\ (MOSCOW UNIVERSITY FOR THE HUMANITIES)}

The article examines the system of corporate governance in Japan as a phenomenon stemming from the synthesis of ethics, aesthetics and religion. Our methodological approach, based on a comprehensive study of the philosophical foundations of the Japanese structure of corporate management, helped us trace the inextricable link between the religious and philosophical interpretations of power, principles of tolerance, traditional social concepts and speech etiquette.

Our study focuses on the uniqueness of the original Japanese interpretation of authority, deeply rooted in Shinto and Confucian thought. Japanese style of corporate governance strongly emphasizes not only the order of subordination, but also absolute harmony of co-being at all stages of life. The principle of 'wa' (harmony) should be interpreted through the concepts of 'ittaikan' (feeling of unity), 'oyakokankei' (parent-child relations) and 'amae' (feeling of dependence).

Governance in Japan is seen as an art endowed with a rich variety of expressive forms. Among them are the decision-making technique known as 'nemawashi' (going around the root), the 'settoku' (a persuasion-based communication style), and the 'ishindenshin' (communication 'from heart to heart').

The article also traces the deep two-way correlation between the philosophy of tolerance and the art of governance in Japanese tradition, with a special focus on the social and philosophical concepts underpinning the hierarchical structure of Japanese society.

In contemporary Japan, the abovementioned traditional concepts go beyond pure theory, shaping the mechanism of governance on all levels - from small groups to large enterprises, companies and the state in general. The hierarchical structure of Japanese governance can thus be presented as a holistic entity, revealing a specific ontology; a worldview, as well as the mechanism of management which helps the economy sustain a high rate of development. 
Keywords: Japan, management, concept of governance, Japanese etiquette, traditions in Japan, Japanese style of communication

\section{REFERENCES}

Arskaia, L. P. (1991) Iaponskie sekrety upravleniia [Secrets of Japanese governance]. Moscow, Universum Publ. 118 p. (In Russ.).

Vasilenko, I. A. (2000) Politicheskaia globalistika : ucheb. posobie dlia vuzov [Political global studies : A textbook for higher school]. Moscow, Logos. 360 p. (In Russ.)

Veretnov, V. I. (2009) Iaponskii opyt upravleniia biznesom [Japanese experience in managing a business]. Proza.ru [online] Available at: http://www.proza.ru/2009/10/11/919 (access date: 12.12.2015). (In Russ.).

Gvozdevskaia, G. A. (2013a) Ierarkhicheskaia struktura iaponskoi filosofii, sotsiuma, iazyka: obraztsy $\mathrm{i}$ ispolnenie [Hierarchical structure of Japanese philosophy, society and language: Models and their implementation] In: Kul'tura - ravnovesie $i$ garmoniia budushchego mira [Culture: equilibrium and harmony of the world to come]. Moscow, Akademiia GPCh MChS Rossii. 192 p. Pp. 44-49. (In Russ.).

Gvozdevskaia, G. A. (2013b) Etiket kak glavnaia sostavliaiushchaia ierarkhicheskogo poriadka iaponskogo sotsiuma [Etiquette as the main constituent element of hierarchical order in Japanese society]. In: Materialy mezhdistsiplinarnoi nauchno-prakticheskoi konferentsii s mezbdunarodnym uchastiem "Kul'tura i bezopasnost' $v$ sovremennom mire» [Culture and security in contemporary world: Proceedings of international interdisciplinary conference]. Moscow, Akademiia GPCh MChS Rossii. 229 p. Pp. 84-86. (In Russ.).

Karelova, L. B. (2013) Printsipy buddiiskoi i konfutsianskoi etiki v formirovanii kontseptsii korporativnoi sotsial'noi otvetstvennosti v sovremennoi Iaponii [Principles of Buddhist and Confucian ethics in the rise of the concept of corporate social solidarity in contemporary Japan]. Iaponiia, no. 42, pp. 89-100. (In Russ.).

Kuritsyn, A. N. (1994) Sekrety effektivnoi raboty: opyt SShA i Iaponii dlia predprinimatelei $i$ menedzherov [Secrets of efficient work: The experience of USA and Japan for businessmen and managers]. Moscow, Izdatel'stvo standartov. 197 p. (In Russ.).

Knorring, V. I. (2001) Teoriia, praktika i iskusstvo upravleniia : uchebnik dlia vuzov po spetsial'nosti "Menedzbment» [Theory, practice and the art of management: a textbook for management majors]. 2nd edn, augm. and exp. Moscow, NORMA Publ. (NORMA - INFRA-M). 528 p. (In Russ.).

Kozlov, A. A. (2002) Upravlenie personalom v iaponskikh korporatsiiakh v usloviiakh globalizatsii ekonomiki [Personnel management in Japanese corporations in globalized economy]. Menedzhment $v$ Rossii $i$ za rubezhom, no. 2, pp. 122-128. (In Russ.)

Liker, J. (2012) Dao Toyota: 14 printsipov menedzbmenta vedushchei kompanii mira [The Toyota Way: 14 Management Principles from the World's Greatest Manufacturer]. Moscow, Al'pina Publisher. 412 p. (In Russ.).

Mil'don, V. I. (1992) Beskonechnost' mgnoveniia (natsional' noe v kbudozhestvennom soznanii) [The endless moment: The national in artistic consciousness]. Moscow, Sovetskii pisatel' Publ. 432 p. (In Russ.).

Keieirinen [The philosophy of governance]. Panasonic (official site) [online] Available at: http://www.panasonic.com/jp/corporate/management/governance.html (access date: 01.01.2016).

Simkhovich V. A. (2002) Istoki sovremennoi iaponskoi sistemy upravleniia [Origins of contemporary Japanese system of governance]. Problemy teorii i praktiki upravleniia, no. 6, pp. 114-120. (In Russ.).

Tarasova, T. V. (2003) «Tri kita» iaponskogo marketinga [The three pillars of Japanese marketing]. Marketing $v$ Rossii i za rubezhom, no. 6, pp. 119-135. (In Russ.).

Sharko, M. V. (2007) Iaponskaia vezhlivost' i natsional'no stilizovannye konstanty diplomatii [Japanese politeness and nationally adapted basics of diplomacy]. Polignozis, no. 1 (29), pp. 96-105. (In Russ.). 
Arbor, A. (1995) Nemawashi essential for conducting research in Japan. Social science \& medicine, no. 41 (3) [online] Available at: http://www.ncbi.nlm.nih.gov/pubmed/7481931\# (access date: 12.12.2015).

Doi Takeo (2002). The Anatomy of Dependence. Toukyou : Kodansha. 192 p.

Nakane Chie (1967) Tateshakai no ningen kankei: tan'itsu shakai no riron [Human relations in Japan]. Tōkyō : Kōdansha, Shōwa 42. 189 p. (In Japanese).

Yoshimori Masaru (1998) Kigyou wa dare no mono ka. Kigyougainen no nichibeiouhikaku [Who owns the company? A comparison of business ownership concepts in Japan, USA and Europe]. Niftyhomupejisabisu [online] Available at: http://myoshimori.world.coocan.jp/papers/6.pdf (access date: 15.01.2016). (In Japanese).

Submission date: 15.01 .2016$.

Гвоздевская Галина Анатольевна - кандидат педагогических наук, доцент кафедры иностранных языков и лингвистики факультета международных отношений и туризма Московского гуманитарного университета. Адрес: 111395, Россия, г. Москва, ул. Юности, д. 5. Тел.: +7 (495) 374-69-35. Эл. aspec: ongaku3@mail.ru

Gvozdevskaia Galina Anatolyevna, Candidate of Pedagogy, Associate Professor, Department of Foreign Languages and Linguistics, Faculty of International Relations and Tourism, Moscow University for the Humanities. Postal address: 5 Yunosti St., Moscow, Russian Federation 111395. Tel.: +7 (495)374-69-35.E-mail: ongaku3@mail.ru 